\title{
Interpersonal Service Support Based on Employee's Activity Model
}

\author{
Kentaro Watanabe and Takuichi Nishimura \\ National Institute of Advanced Industrial Science and Technology, \\ Center for Service Research, Tokyo, Japan \\ \{kentaro.watanabe, takuichi.nishimura\}@aist.go.jp
}

\begin{abstract}
To improve the productivity of services and satisfy both customers and employees, the activity support by means of IT systems is effective. However, it is rather difficult to support employees' activities in interpersonal services such as nursing care with IT systems. One of the main reasons is that they are required to respond to requests from customers or coworkers flexibly and their activity cannot be described in a formal and sequential manner. To develop a effective system to support such activities, analysis on triggers to perform tasks, criteria to prioritize them, and concrete means to perform them are necessary. However, there are few methods to determine which aspects of employee's activities should be supported in a simple manner.

In this report, the authors propose an employee's activity model and its usage for the support of interpersonal services. In addition, the authors introduce an example case of activity analysis and support planning of a nursing care service by means of the proposed model.
\end{abstract}

Keywords: Intelligent systems, Humanization of work, Service Engineering, Employee's activity model.

\section{Introduction}

Service industry takes a dominant role in most of developed countries. Meanwhile, many services are still labor-intensive and working environments tend to be hard. Generally, the activity support by means of IT systems is effective to improve the productivity of services and to satisfy not only customers, but also employees. However, it is rather difficult to support employees' activities in interpersonal services such as nursing care, retailing and restaurant services with IT systems. One of the reasons is that employees for these services should respond to requests from customers or coworkers flexibly [1] and their activity cannot be described in a formal and sequential manner, which makes the adaption of ordinary Systems Engineering approach difficult (For example, [2]). In addition, it is not usually acceptable for customers to replace human-to-human interactions in interpersonal services with IT systems. Therefore, an indirect support for employees' activities is preferable in many cases. 
To develop an effective system to support employees, it is important to understand how they perform their complicated tasks. For this purpose, the deep analysis on their way of work, such as triggers to perform tasks and criteria to prioritize them is necessary. Though various models and methods to describe characteristics of human behavior such as its cognitive process for designing interfaces between users and systems (For example, [3-5]), there are few methods to determine which aspects of employee's activities should be supported in a simple manner.

In this report, the authors propose an employee's activity model to describe these aspects, and its usage for the support of interpersonal services. In addition, the authors introduce an example case of the activity analysis and support planning of a nursing care service by means of the proposed model. Based on the case study, the authors discuss the effectiveness of the proposed model and future researches.

\section{Employee's Activity Model and Its Usage}

\subsection{Employee's Activities in Interpersonal Services}

In this report, the authors focus on interpersonal services that are to create value through interactions between a person and a person (in most cases, an employee and a customer). A nursing care service in a hospital or a facility for elderly people is a typical example of interpersonal services. In addition, interactions with customers in a retail store or a restaurant are also categorized into interpersonal services.

In such interpersonal services, activities of each employee directly influence the quality of the service and satisfaction of their customers. Human behaviour is not necessarily stable. Human errors easily cause the dissatisfaction of customers and even crucial in medical services for example [6]. Meanwhile, the judgement of situations by humans and human-to-human interactions are not easily replaced with machines or automated systems. Therefore, the role of IT systems in interpersonal services tends to support employees' activities.

\subsection{Existing Models on Employee's Activities}

To support employees' activities, it is necessary to determine the tasks to be supported and how to support them. For that purpose, various analysis and modeling methods have been proposed.

Sequential process modeling methods are commonly applied in software or systems engineering. For example, the activity diagram in the Unified Modeling Language (UML) [7] can describe human activities as sequential processes. Business Process Modeling Notation (BPMN) is also a famous modeling method for reengineering business processes [2]. These process modeling methods are useful to analyze stable and common processes and to replace them with automated process of IT systems. However, the support for employees' activities in response to various requests and situations is not within the focus of these models.

Meanwhile, there are numerous analysis and modeling methods on characteristics of human behavior. For example, Card et al. [5] describe the information process of 
humans. Such an information process model is useful to provide standards for the interface of IT systems such as responsiveness. There are also researches on physical features of human behavior [8]. They are effective to lighten the load of a certain movement in a service activity. However, there are few methods to determine which kinds of employee's activities should be supported in a simple manner. A holistic model of human activities would be effective to determine a concept of a support system, especially for interpersonal services.

\subsection{Employee's Activity Model}

In this section, the authors introduce an employee's activity model (see Fig.1). To develop this model, the authors focus on employees' information processing sequence and their actual activities. The proposed model is developed based on the information process model such as [5] and the result of informal interviews and observation in three kinds of interpersonal service fields.

In this model, triggers of employees' activities are given by two types of 'input', which are 'plan' and 'event'. Plan is information on activities scheduled beforehand. Event is information from customers or other employees to trigger a new activity which is not scheduled in advance. An activity corresponding to each plan or event is called as a 'task.'

Contents of a planned task that is a task corresponding to a plan are usually determined beforehand. Meanwhile, an event task that corresponds to an event depends on the requests and situation. Event tasks can be categorized into the following two types. One of the types is an explicit event task that is performed in response to explicit requests from other employees or customers. The other type is an implicit event task that is performed based on the employee's own awareness on the situation in a service field or an attitude of others.

These tasks are retained in the memory of the employee, which is named as 'pool.' The tasks in the pool are prioritized based on the employees' judgment using "operational information" and "priority rule." Operational information is about customers,

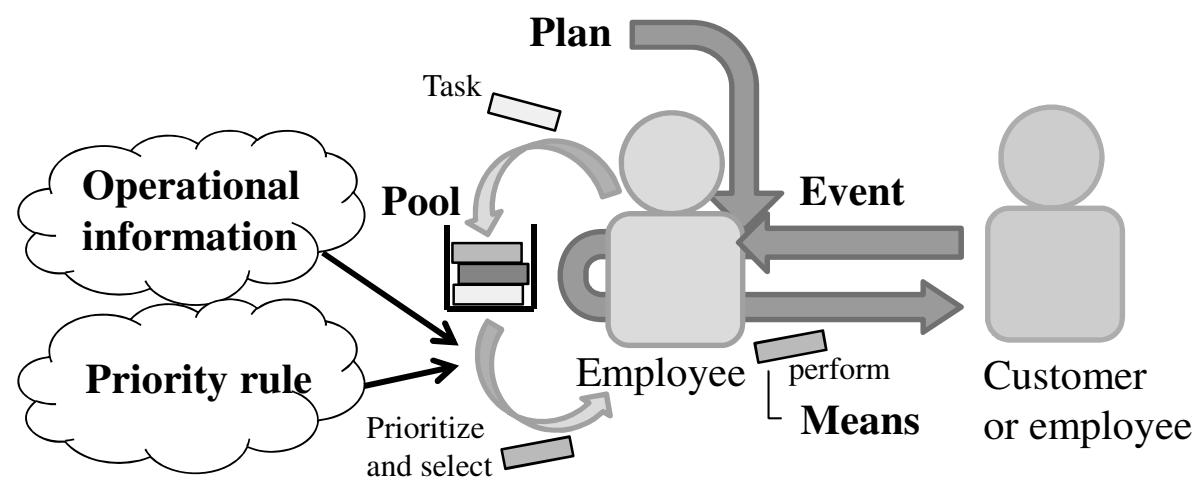

Fig. 1. Employee's activity model 
employees and related issues in a service field for service activities, such as characteristics of customers. Priority rule is a fundamental rule to determine the priority of tasks. After the prioritization of tasks, a selected task is actually performed to a customer or a coworker. To perform a task, a certain means is applied.

The employee's activity model provides a basic framework to analyze tasks performed in a service field. The result of analysis is utilized to determine the specification of a support system for interpersonal services as is explained in the next session.

\section{Activity Analysis and Support Based on the Employee's Activity Model}

\subsection{Approaches}

In this report, the authors propose an approach of activity analysis and support based on the proposed model. This approach consists of the following three steps.

\section{Observing employees' activities}

The first step is to observe employees' activities in a service field and to record them. Manual observation methods of human activities such as time and motion study [9] will be effective. In addition, sensing devices of human behaviors and methods to estimate actual activities are also applicable, such as [10]. The items to be observed and recorded are time, frequency and period of each task, its performer and the elements of the employee's activity model such as events and means. In addition, supplemental information such as an activity's importance for customers and physical or mental costs to perform a task are effective to determine tasks to be supported at the later step. Since the information process to determine tasks are not necessarily visible, questionnaire, interviews and other qualitative research approaches should be applied if necessary. When recording the activities, it is also important to develop codes to determine the classification and description of employees' activities for the statistical analysis [1].

\section{Specifying tasks to be supported}

The second step is to analyze the recorded activities for specifying tasks to be supported. According to the concern of a service field or its manager, the evaluation criteria to determine tasks to be supported should be determined. In addition to the frequency and period of each task, the aforementioned importance for customers and costs for employees can be taken into consideration.

3. Making concepts to support the specified tasks

The last step is to make a concept to support the specified tasks. For this purpose, the authors suggest typical support approaches for the elements of the employee's activity model as are summarized in Fig.2. In these support approaches, training and education for employees are not included. Though they are important and effective supports 
for employees, the authors focus on the system development for the direct implementation to a service field in this report.

- Plan

A plan for services should be correctly notified to adequate employees and its result should be managed. The plan management is a common approach for this purpose. As concrete support functions, announcement of future tasks and mechanisms to confirm the completion of tasks can be developed.

\section{- Event}

An explicit event which is a clear request from other employees and customers can be handled or at least noticed even by novices. Meanwhile, it is more difficult to notice an implicit event and react to it. Visualization of events mainly focuses on implicit events which require employees to acknowledge the necessity to perform certain tasks. A nurse call button is a typical example to express requirements of patients who cannot show their requests.

- Pool

The human memory has a limited capacity and tends to lose its content. In the interpersonal services, interruptions to tasks occurs often [11]. After several interruptions occurred during a certain task, it is difficult to remember doing it again after the interruptions. To externalize the memory is effective not only for novices but also for those who have sufficient experiences. For example, voice recording is useful for this purpose.

- Operational information

In addition to information included in plan or event, various kinds of operational information are required to perform tasks. For example, customers' previous experience on services is valuable information for better services. A system to search for and view required information on customers or tasks and to leave messages on tasks for other employees would be effective for this purpose.

- Priority rule

The priority rule of each employee can be various, which affects the quality and efficiency of his / her service. The decision support for each employee may decrease the variability of his/her activities. For example, task recommendation would be effective during a service activity, though its implementation for on-time support is quite difficult.

- Means

In interpersonal services, tasks are basically performed by humans. However, it is preferable to support high-load tasks to prevent injury. The support for such tasks can be realized by mechanical systems. For example, the robotics technology is a promising technology for this purpose. 
Elements in employee's activity model

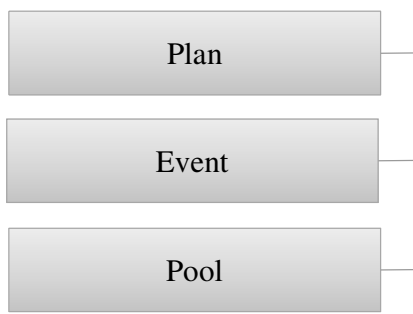

Operational information

Priority rule Means
Support concepts

for employee's activities

Plan management

(ex. task scheduling)

Visualization of event

(ex. visualizing intentions of customers)

Externalization of memory

(ex. short memo, voice recording)

Management / Sharing of operational information

(ex. knowledge management)

Decision support

(ex. task recommendation)

Enforcement/Automation of operation

with mechanical systems (ex. service robots)

Fig. 2. Support concepts for employee's activities

By applying these steps, concepts of support systems for interpersonal services can be extracted.

\subsection{Case Study}

As a case study, the authors applied the proposed model and approach to the observation results of an actual nursing care service in a nursing care facility named as Wakoen and extracted some concepts for employee's activity support. This observation results consist of seven employees' activity data: four care workers, two nurses and one occupational therapist. The information on tasks was gathered by the time and motion study performed for three days.

According to the aforementioned approach, the authors extract tasks with higher frequency and make the concepts to support them using the employee's activity model.

\subsection{Results}

Table 1 shows ten most frequent tasks of each kind of employee. First, "information sharing", "making records" and "confirming records" are the common tasks for several kinds of employees. These tasks are especially expected to be improved by information systems. "Talking to residents" is also a common task for all the kinds of employees. This task is a characteristic one in a nursing care service to extract implicit events from elderly people. Meanwhile, the specialized tasks for each kind of employees were also extracted such as "measurement of vital signs" for nurses, "physical therapy" for occupational therapists and "wheel chair guidance" for care workers. 
Table 1. Frequently performed tasks in the nursing-care service

\begin{tabular}{|c|c|c|c|}
\hline & \multirow[t]{2}{*}{ Planned task } & \multicolumn{2}{|l|}{ Event task } \\
\hline & & Explicit & Implicit \\
\hline Care worker & (none) & $\begin{array}{l}\text { - Information } \\
\text { sharing }\end{array}$ & $\begin{array}{l}\text { - Wheel chair guidance } \\
\text { - Transfer assistance } \\
\text { - Talking to residents } \\
\text { - Watching residents } \\
\text { - Hand washing } \\
\text { - Making records } \\
\text { - Confirming records }\end{array}$ \\
\hline Nurse & $\begin{array}{l}\text { - Maintenance of gastric } \\
\text { fistula } \\
\text { - Measurement of vital } \\
\text { signs (temperature, } \mathrm{SpO} 2 \text {, } \\
\text { others) }\end{array}$ & $\begin{array}{l}\text { - Information } \\
\text { sharing }\end{array}$ & $\begin{array}{l}\text { - Talking to residents } \\
\text { - Making records } \\
\text { - Confirming records }\end{array}$ \\
\hline $\begin{array}{l}\text { Occupational } \\
\text { therapist }\end{array}$ & $\begin{array}{l}\text { - Physical therapy } \\
\text { (massage, walking training, } \\
\text { standing training) }\end{array}$ & $\begin{array}{l}\text { - Information } \\
\text { sharing }\end{array}$ & $\begin{array}{l}\text { - Wheel chair guidance } \\
\text { - Transfer assistance } \\
\text { - Talking to residents } \\
\text { - Making records } \\
\text { - Confirming records }\end{array}$ \\
\hline
\end{tabular}

Table 2. Concepts of an activity support system for occupational therapists

\begin{tabular}{|l|l|l|}
\hline $\begin{array}{l}\text { Target } \\
\text { operations }\end{array}$ & $\begin{array}{l}\text { Elements in employee's } \\
\text { activity model }\end{array}$ & $\begin{array}{l}\text { Concepts of } \\
\text { activity support }\end{array}$ \\
\hline Physical therapy & Plan & $\begin{array}{l}\text { Management system of } \\
\text { therapy plan }\end{array}$ \\
\hline $\begin{array}{l}\text { Information } \\
\text { sharing }\end{array}$ & Operational information & $\begin{array}{l}\text { Mobile device for } \\
\text { information sharing }\end{array}$ \\
\hline $\begin{array}{l}\text { Transfer } \\
\text { assistance }\end{array}$ & Means & Transfer support robots \\
\hline $\begin{array}{l}\text { Talking to } \\
\text { residents }\end{array}$ & Event & $\begin{array}{l}\text { Indication system of } \\
\text { residents' intent }\end{array}$ \\
\hline $\begin{array}{l}\text { Making / } \\
\text { confirming } \\
\text { records }\end{array}$ & Operational information & $\begin{array}{l}\text { Mobile device for } \\
\text { information sharing }\end{array}$ \\
\cline { 2 - 3 } & Pool & Voice recording \\
\hline
\end{tabular}

Next, support concepts for these tasks of each kind of employees were extracted. Table 2 shows the support concepts for occupational therapists. For "physical therapy" as a planned task, a management system of a therapy plan was considered. For "talking to residents" to extract implicit events, a sensing system or an interface 
to detect the residents' demands and to visualize them was considered. It should be noted that this concept is just a supplemental system and cannot replace the basic communication between residents and employees. A mobile device system for information sharing was considered to support "information sharing", "making records" and "confirming records." In addition, voice recording is effective approaches to make temporary records instantly. A transfer support robot would be an effective approach to help a high-load task as "transfer assistance."

\section{Discussion}

As can be seen in Table 2, various kinds of support concepts can be obtained from the aspect of the proposed model. A mobile system for information sharing is actually under development. Meanwhile, it is preferable to consider multiple criteria to determine a support target such as customer value, cost for employees, and risk in tasks, though the frequency of tasks is also an effective criterion. How to determine such criteria would be an important strategy to improve interpersonal services.

In the proposed model, a task is described as a single, inseparable one. Meanwhile, Tukker and Spear [6] noticed that the nurses in hospitals use three strategies to complete their tasks: separating, interweaving and reprioritizing their tasks. How to analyze a large portion of tasks within the proposed model is a remaining issue in the future.

As another issue to be discussed, how to describe an interpersonal service as teamwork should be considered. In the proposed model, interactions between employees are taken into consideration. However, how employees work as a team dynamically and how these processes can be improved are not mentioned sufficiently. This issue remains also as a future research.

Currently, the employee's activity model is used as a framework to determine support concepts of employees' activities. When more information on the employee's activity model can be gathered, the numerical evaluation of support concepts such as changing the priority rules and applying IT systems to a service field can be performed by computational methods such as the multi-agent simulation [12].

\section{Conclusion}

In this study, the authors proposed the employee's activity model to analyze an employee's activity and to support it. In the future research, the authors will refine the related methods based on the proposed model, and validate them through actual system development.

Acknowledgement. We appreciate the sincere support for this study by Wakoen and our colleagues, Hiroyasu Miwa and Tomohiro Fukuhara. 


\section{References}

1. Miwa, H., Fukuhara, T., Nishimura, T.: Service Process Visualization in Nursing Care Service Using State Transition Model. In: 4th International Conference on Applied Human Factors and Ergonomics, CD-ROM (2012)

2. Havey, M.: Essential Business Process Modeling. O'Reilly Media (2005)

3. Davis, F.D.: A Technology Acceptance Model for Empirically Testing New End-User Information Systems: Theory and Results, Doctoral Dissertation. MIT Sloan School of Management, Cambridge (1986)

4. Lin, C.J., Yang, C.-W., Lin, S.-B., Lin, S.-F.: A Human Factors Model for Enterprise Resources Planning System Implementation. In: Smith, M.J., Salvendy, G. (eds.) HCI International 2009, Part I. LNCS, vol. 5617, pp. 123-130. Springer, Heidelberg (2009)

5. Card, S.K., Moran, T.P., Newell, A.: The Model Human Processor: An Engineering Model of Human Performance. In: Boff, K.R., Kaufman, L., Thomas, J.P. (eds.) Handbook of Perception and Human Performance, vol. 2, pp. 1-35. Wiley-Interscience, New York (1986)

6. Tukker, A.L., Spear, S.J.: Operational Failures and Interruptions in Hospital Nursing. HSR: Health Services Research 41(3), 643-662 (2006)

7. Object Management Group (OMG): OMG Unified Modeling Language (OMG UML), Infrastructure Version 2.3 (2010)

8. Nemeth, C.P.: Human Factors Methods for Design. CRC Press, Boca Raton (2004)

9. Zheng, K., Guo, M.H., Hanauer, D.A.: Using the Time and Motion Method to Study Clinical Work Processes and Workflow: Methodological Inconsistencies and a Call for Standardized Research. J. American Medical Informatics Association 18, 704-710 (2011)

10. Pentland, A.: Automatic Mapping and Modeling of Human Networks. Physica A: Statistical Mechanics and its Applications 378(1), 59-67 (2007)

11. Kasahara, S., Ohno, Y., Ishii, A., Numasaki, H.: Visualizing the Impact of Interruptions in Nursing Workflow using a Time Process Study. IT Healthcare 5(2), 124-134 (2010)

12. Ferber, J.: Multi-Agent System: An Introduction to Distributed Artificial Intelligence. Addison-Wesley, New York (1999) 